\title{
Toward parameterization of spin-orbit coupling in triplet organic diradicals separated by a partially conjugated spacer
}

\author{
Andrei G. Kutateladze* and William A. McHale, Jr. \\ Department of Chemistry and Biochemistry, University of Denver, 2190 E. Iliff Ave. F.W. Olin \\ Hall, 202, Denver, CO 80208-2436 \\ E-mail: akutatel@,du.edu
}

\section{Dedicated to Professor Nikolai S. Zefirov on the occasion of his $\mathbf{7 0}^{\text {th }}$ birthday}

(received 04 Jan 05; accepted 10 Feb 05; published on the web 26 Feb 05)

\begin{abstract}
$\mathrm{Ab}$ initio computations were carried out to map singlet-triplet spin-orbit coupling (SOC) matrix elements onto the complete conformational space of four triplet organic 1,3 and 1,4 diradicals. The previously postulated conformational dependence of SOC in simple diradicals based on the "sine", or "90-degree rule" was shown not to be satisfactory for quantitative estimates. Based on the analysis of localized pre-NHO contributions, a much more precise parametric equation is developed for 1,3-trimethylene. It is demonstrated that the case of the more complex 1,4diradicals of general structure. $\mathrm{C}-\mathrm{C}-\mathrm{X}-\mathrm{C}$ or $\mathrm{C}-\mathrm{C}-\mathrm{X}-\mathrm{Z}$, where one of the two radical centers is "partially" conjugated through $\mathrm{X}(\mathrm{O}$ or $\mathrm{C}=\mathrm{C})$, can be easily reduced to the parent trimethylene case, allowing for a generalized treatment of SOC matrix elements in triplet organic diradicals.
\end{abstract}

Keywords: Organic diradicals, spin-orbit coupling (SOC), inter-system crossing (isc), ab initio, parameterization

\section{Introduction}

Non-adiabatic processes in organic triplet species and diradicals constitute one of the most intricate areas of mechanistic organic photochemistry. Ever since Salem and Rowland, in their 1972 seminal paper, ${ }^{1}$ laid the foundation for quantitative description of diradical properties, there have been numerous attempts made to advance our understanding of organic diradicals, ${ }^{2}$ most notably, the rigorous reformulation of Salem's rules by Michl. ${ }^{4 a}$ One of the most intriguing aspects of diradical reactivity is the problem of singlet-triplet surface hopping, which is the cornerstone of theoretical and experimental organic photochemistry. It is generally believed that inter-system crossing (ISC) in short $(1,3$ and 1,4) triplet diradicals is controlled by spin-orbit coupling (SOC) and there is evidence that SOC dominates over electron-nuclear hyperfine 
coupling (HFC) even in longer $1, n$-diradicals. ${ }^{3}$ Unlike HFC, spin-orbit coupling is strongly conformationally dependent as shown in many studies that addressed structural effects on SOC in triplet organic species. ${ }^{4}$ However, the systematic studies of the conformational dependence of SOC in organic diradicals are lacking, and until very recently there was, in fact, only one rigorous theoretical treatise ${ }^{5}$ of the SOC conformational dependence in trimethylene. There were several semi-quantitative generalization attempts, the most notable being the "sine" (or "ninetydegree") rule. According to Doubleday and co-authors, spin-orbit coupling in polymethylenes and radical pairs generally follows an empirical sine relation whereby the overall SOC value is proportional to the sine of the angle between two odd-electron p-orbitals and to a function including the overlap between the orbitals. ${ }^{5}$ Although based on the correct premise that the atomic spin-orbit integrals are indeed maximized when the inter-orbital angle is $90^{\circ}$, the ninetydegree rule overlooks the fact that the actual $\left\langle\mathrm{p}_{1} \| \mathrm{p}_{\mathrm{n}}\right\rangle$ cross-term contributions in organic diradicals and triplet species constitute at most $5 \%$ of the overall spin-orbit coupling in the vicinity of maximum SOC. The latter was shown by Zimmerman and Kutateladze: $:^{\text {td-f }}$ in the Weinhold's pre-NHO basis it is the same center (local) contributions of type $\left\langle\sigma_{1} \| p_{1}\right\rangle$ and $<\sigma_{\mathrm{n}} \| \mathrm{p}_{\mathrm{n}}>$ which matter the most.

One of the ubiquitous organic 1,4-diradicals is the triplet Paternò-Büchi intermediate. An excellent experimental and theoretical work on Paternò-Büchi mechanism by Caldwell, ${ }^{6}$ published in early $80 \mathrm{~s}$, gave a qualitative explanation to increased spin-orbit coupling in the triplet diradical of type CCOC. He suggested that the reason for the lifetime-shortening effect of $\beta-\mathrm{O}$ is the decreased average distance between the unpaired electrons due to the resonance form shown below.

$$
\mathrm{C}^{\uparrow}-\mathrm{C}-\mathrm{O}-\mathrm{C}^{\uparrow} \leftrightarrow \quad \mathrm{C}^{\uparrow}-\mathrm{C}-\mathrm{O}^{+\uparrow}-\mathrm{C}^{-}
$$

He also suggested that the increase in SOC may be derived from conformations which provide an angle of approximately $90^{\circ}$ between the oxygen $2 \mathrm{p}$ orbital and the half-filled $\mathrm{p}$ orbital at the adjacent terminus. However incomplete, this was the first attempt to expand Salem's ${ }^{1}$ basic conformational reasoning onto a more complex situation. Later computations were carried out on tetramethylene and 2-oxatetramethylene to evaluate SOC matrix element. It was noted in a review article that tetramethylene in several conformations showed SOC of ca. $0.013-0.03 \mathrm{~cm}^{-1}$, whereas its $\beta-O$ counterpart in analogous conformations afforded values of $0.35-0.8 \mathrm{~cm}^{-1}$. Unfortunately the details of these computations were never published and a rationale for this behavior was lacking. In 2001 we conducted a systematic ab initio study of conformational behavior in the parent C-C-O-C diradical, ${ }^{4 \mathrm{k}}$ which gave solid foundation for generalizations and prompted us to attempt parameterization of the SOC conformational dependence.

The goal of the studies presented in this paper is twofold. First of all, it is an theoretical/computational study to determine the conformational dependence of spin-orbit interactions in complex organic diradicals and triplet species. The second and more general goal is to develop a straightforward approach to SOC (and conceivably other relativistic corrections to the Hamiltonian) evaluations using the familiar apparatus of the (classical) organic structural 
theory and hybridization theory, which are better understood by the organic community. Thus, we present the results of our theoretical studies to develop a unified parameterization scheme for modeling SOC (and predicting ISC) for several most critical organic triplet diradicals.

\section{Results and Discussion}

Figure 1 presents the three organic 1,n-diradicals separated by a partially conjugated spacer ${ }^{8}$ which are the focus of our computational studies. These are the intermediate 1,4-diradicals in Paternò-Büchi photoaddition (1), the species resulting from the formal addition of triplet oxygen to ethylene (2), and 2-penten-1,5-diyls (3, both cis- and trans), i.e. the diradicals of general type CCXC and CCXZ, where $\mathrm{X}$ is a fragment capable of conjugation with one of the diradical centers, e.g. a $\pi$-bond or a heteroatom bearing a lone pair (arbitrary conformations are shown).

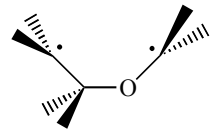

1

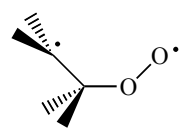

2

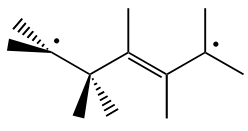

3

\section{Figure 1}

First we consider species $\mathbf{2}$. Our computational finding was that for the triplet diradical $\mathbf{2}$ it is the conformation depicted in Figure 2 which gave the maximum spin-orbit coupling. The torsional (dihedral) angle $\mathrm{C}-\mathrm{C}-\mathrm{O}-\mathrm{O}$ in this conformation is about 110 degrees, and the terminal methylene is rotated by about $80^{\circ}$ out of the C-C-O plane. Full optimization of triplet geometry at the MP2/6-31G(d) level shows that the terminal methylene is slightly pyramidal; the deviation from planarity being ca. 10 degrees.

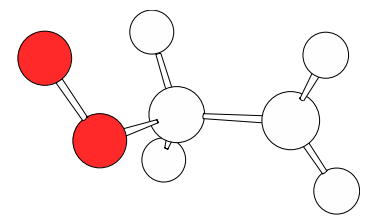

Figure 2. Maximum SOC conformation in diradical 2.

For computational simplicity this methylene group was made planar, and a two-dimensional scan was carried out incrementing the dihedral angle C-C-O-O every 10 degrees and rotating the terminal methylene with the same step. The analysis of the CASSCF energy separating triplet and singlet states shows that the singlet-triplet energy gap is within $1 \mathrm{kcal} / \mathrm{mol}$ throughout. The small singlet-triplet separation suggested that the evaluation of spin-orbit coupling constants is 
very relevant here to accurately predicting ISC. We have obtained SOC values at CASSCF(4,4)/6-31G(d) level for more than 300 geometries on the potential energy surface using the state-averaged approach of Robb as implemented in Gaussian 98, ${ }^{9}$ see Figure 3. It is seen easily that the two-dimensional dependence of SOC has a noticeable maximum.

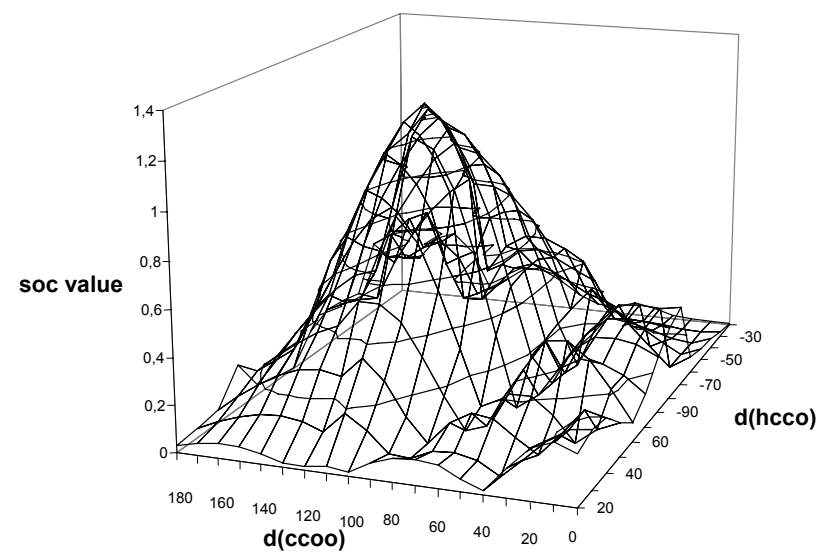

Figure 3. Spin-orbit coupling as a function of two dihedral angles in 2.

Strikingly, this maximum is not at the conformation where the two radical centers are the closest to each other (i.e. s-cis conformation) but rather where the CCOO dihedral angle is about 110 degrees.

In the mid 90's Zimmerman and Kutateladze developed a novel dissection ${ }^{4 d-f}$ of spin-orbit coupling contributions employing Weinhold's Natural Bond Orbital (NBO) analysis ${ }^{10}$. This approach proved to be a powerful tool for analysis of SOC in terms of a simple hybridization theory, preserving at the same time the accuracy of a rigorous quantum mechanical treatment.

Application of Weinhold's analysis to the case of 1,4-diradical 2 allows one to immediately recognize the reason why 2 behaves differently from, say, tri- or tetramethylene-diyls. The NBO population of one of the lone pairs on $\mathrm{O}(3)$ is found to be considerably below 2.0 (see Figure 3).

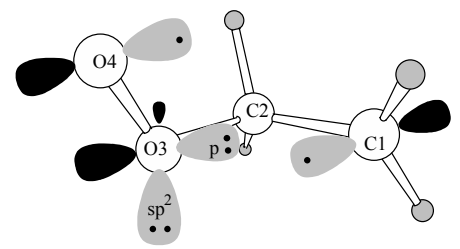

Figure 4. Hybrids contributing the most toward spin-orbit coupling in diradical 2 ( $\sigma$-hybrids omitted for simplicity). 
That is, it is not a lone $\underline{P A I R}$ in this conformation anymore. Thus, we realized that the whole situation is in fact reminiscent of the trimethylene case (cf. Figure 4). Oxygen-3's p (not $\mathbf{s p}^{2}$ ) orbital serves as a counterpart singly occupied orbital of trimethylene. This is due to the fact that the actual singly occupied orbital at the terminal oxygen (O4) is overlapping heavily with the $2 \mathbf{p}$ orbital at O3, which in turn is exhibiting some "singly occupied character". Thus the $2 \mathbf{p}(\mathrm{O} 3)$ $2 \mathbf{p}(\mathrm{C} 1)$ fragment in diradical $\mathbf{2}$ is, in a way, mimicking the $2 \mathbf{p}(\mathrm{C} 1)-2 \mathbf{p}(\mathrm{C} 3)$ situation in trimethylene.

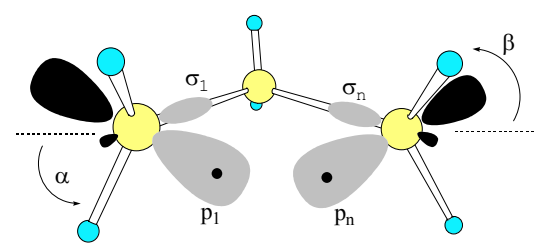

Figure 5. Maximum SOC conformation in trimethylene.

This example provides a clear demonstration of immense potential of organic structural theory and the theory of hybridization. It shows that even a complicated relativistic phenomenon can be dealt with within traditional organic paradigm combined with some additional simple rules such as Doubleday's 90-degree rule (with the reservations presented below) and Zimmerman's "one center only" hybrid contributions. It also demonstrates that the problem of conformational dependence of the SOC matrix element in such triplet species can be tackled by reducing it to the simpler case of SOC dependence in 1,3-propanediyl.

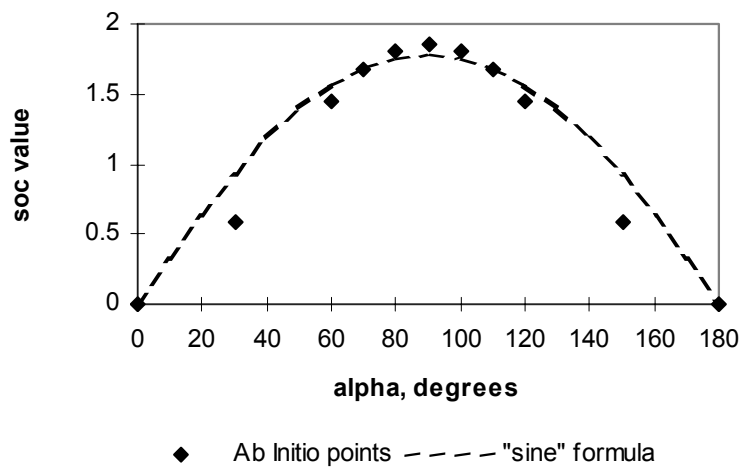

Figure 6. Poor correlation between $a b$ initio $\mathrm{SOC}$ values and the values computed with $\mathrm{SOC}=C$ $S \sin \gamma$ formula (trimethylene $\alpha=90,0<\beta<180$, rms fit is 0.149 ).

How simple is the trimethylene case? As stated in the introduction, the main problem with the 90-degree (or "the sine") rule is that in this model the SOC matrix element is perceived to be a 
product of the direct "through-space" interaction between the odd-electron orbitals. Our previous findings ${ }^{4 d-f}$ suggest strongly that this is not the case and that it is the local, one center interactions which are of principal importance. The mutual orientation of the odd-electron centers is still important, and the way the center 1 "knows" about the center $n$ is through the molecular $\sigma$ framework ("through-bond" interactions). We conducted a two-dimensional SOC scan for trimethylene by rotating the terminal methylenes (dihedral angles $\alpha$ and $\beta$, see Figure 4 ) at the state averaged CASSCF(4,4)/6-31G(d) level of theory ${ }^{11}$ using Furlani's geometry ${ }^{5}$ and found that the "sine" rule does not describe the SOC dependence in this simple system quantitatively. We do not expect the rule to perform any better for structurally more complex species. Figure 6 shows how poor the correlation is between the ab initio SOC elements (solid squares) and ones calculated (dashed line) using the sine formula, $\mathrm{SOC}=C S \sin \gamma$, where $\gamma$ is the angle between the odd-electron orbitals, $S$ is the overlap between the same orbitals (in this particular case the preNHO overlap was used) and $C$ is a fitting constant which was optimized to minimize the rms fitting error.

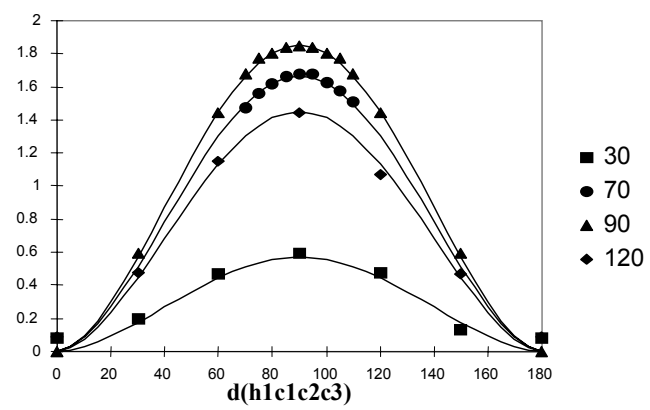

Figure 7. $A b$ Initio (markers) and parametric (solid lines) SOC values for different conformations of trimethylene: $0<\alpha<180, \beta=30,70,90,120$ shown.

Conversely, if the local interactions are indeed controlling, simple MO considerations would imply that, e.g., for an MO SOC term such as $\left\langle\Psi_{\mathrm{HOMO}} \| \Psi_{\mathrm{LUMO}}\right\rangle$ or, for that matter, any combination of active space MOs $\boldsymbol{i}$ and $\boldsymbol{j}\left\langle\Psi_{\mathrm{i}}|| \Psi_{\mathrm{j}}\right\rangle$, it is the cross-overlaps $\left\langle\sigma_{1} \mid \mathrm{p}_{\mathrm{n}}\right\rangle$ and $\left\langle\sigma_{\mathrm{n}} \mid \mathrm{p}_{1}\right\rangle$ which are of importance as far as the "through-bond" communication between the two centers is concerned. It is easy to see that $\left\langle\sigma_{\mathrm{n}} \mid \mathrm{p}_{1}\right\rangle$ and $\left\langle\sigma_{1} \mid \mathrm{p}_{\mathrm{n}}\right\rangle$ are proportional to $\sin \alpha$ and $\sin \boldsymbol{\beta}$ respectively (Figure 4). Thus the problem of a simple geometrical relationship for SOC in trimethylene can, in my view, be reduced to a simple two parameter equation

$$
\mathrm{SOC}=C(\sin \alpha \sin \beta)^{\mathrm{r}}
$$

where $C$ is a maximum SOC value in the vicinity the $\left\{\alpha=90^{\circ}, \beta=90^{\circ}\right\}$ conformation, and $\mathrm{r} \approx$ 1.7 is the only fitting parameter. Figure 6 shows how much better this simple parametric 
equation, $\mathrm{SOC}=1.85(\sin \alpha \sin \beta)^{1.7}$ (solid lines), describes the ab initio SOC values for all the possible $\{\alpha, \beta\}$ conformations studied (rms fit is 0.003 for 129 points).

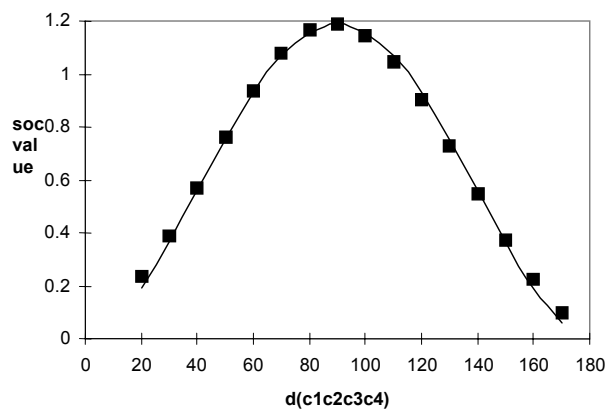

Figure 8. Soc dependence in trans-2-pentene-1,5-diyl, $\alpha=90 ; a b$ initio (solid squares) $v s$. empirical (solid line).

With this in mind we can now examine our computational results on SOC conformational dependence in 2-penten-1,5-diyl (trans- and cis-) 3, see Figure 8. First, an SOC scan was conducted for the trans-isomer at the CASSCF $(4,4) / 6-31 \mathrm{G}(\mathrm{d}) / / \mathrm{ROHF} / 6-31 \mathrm{G}(\mathrm{d})$ level of theory, keeping c1-methylene at $90^{\circ}$ and changing dihedral angle $\mathrm{c} 1 \mathrm{c} 2 \mathrm{c} 3 \mathrm{c} 4$ from 0 to 180 degree (the $\mathrm{c} 3 \mathrm{c} 4 \mathrm{c} 5$ allylic fragment was kept planar). It follows from the computations that the overall problem can indeed be reduced to the trimethylene situation, whereby the maximum SOC is, again, achieved in the vicinity of the $\{90 ; 90\}$ conformation with the odd-electron hybrids $\mathrm{p}_{1}$ and $\mathrm{p}_{3}$ laying nearly in the $\mathrm{c} 1 \mathrm{c} 2 \mathrm{c} 3$ plane.

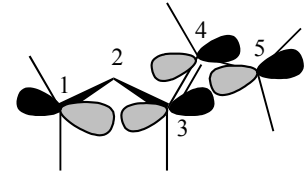

trans-

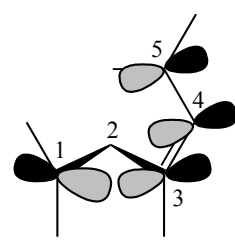

cis-

Figure 9. Cis- and Trans-2-pentene-1,5-diyls.

Once again our parametric equation $\mathrm{SOC}=C(\sin \alpha \sin \beta)^{1.7}$, where $C=1.19$ is the SOC value at $\{90 ; 90\}$, shows remarkable agreement with the $a b$ initio values in this case as well. The rms value for the fit is 0.0054 , see Figure 7 . The rms of the fit for the cis-isomer (0.009) was slightly higher, indicating that bringing $\mathrm{p}_{5}$ closer to $\mathrm{p}_{1}$ introduces small through space perturbation. This rms value, however, is still very low. Thus, the example provides further indication for the generality of this approach. Figure 9 shows the comparison of the 3D SOC dependence obtained 
via $a b$ initio technique with the values calculated using the following parametric equation, SOC $=1.09 \cdot(\sin \alpha \sin \beta)^{1.7}$, where 1.09 is the SOC value for $\{90 ; 90\}$ conformation of cis-isomer.
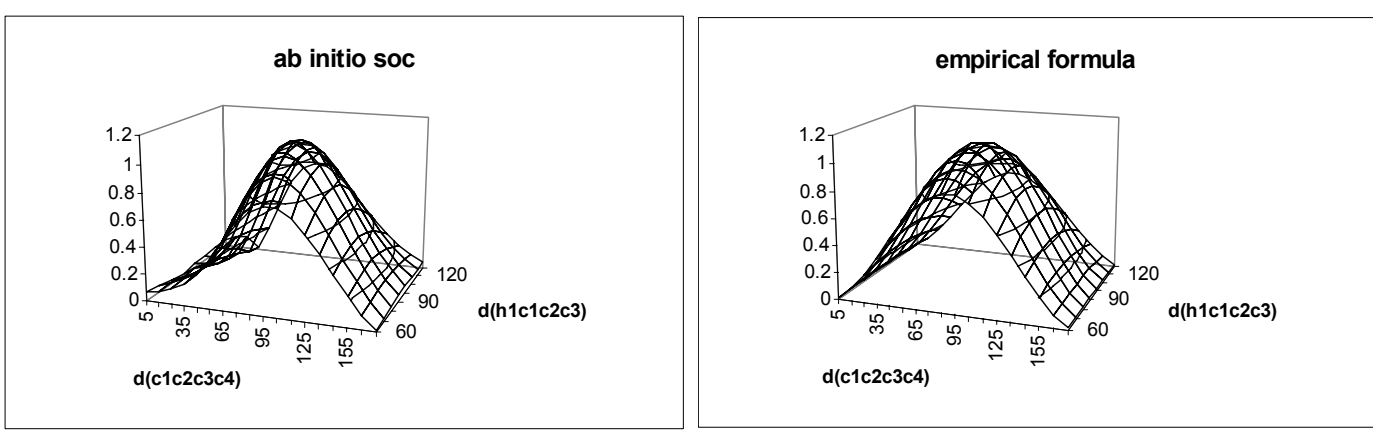

Figure 10. Cis-pentenedyil: $3 \mathrm{D}$ comparison of $a b$ initio and the parametric SOC values for different $\alpha$ (dihedral angle h1c1c2c3) and $\beta$ (dihedral angle c1c2c3c4) values; rms $=0.0095$ for the total of 144 geometries.

Even the magnitude of the pre-multiplier $C$ (1.85 for trimethylene, 1.19 for trans-pentenedyil, 1.09 for cis-pentenedyil) can be semi-quantitatively predicted using simple resonance or Hückel approximation of the spin density on $\mathrm{C} 3$. The spin density at $\mathrm{C} 3$ is expected to be equal (resonance) or slightly higher (Hückel) than that at $\mathrm{C} 5$ in pentenediyls. Thus the $C$-values for the parametric equation describing the two pentenediyls are predicted to be higher than a half of 1.85 (i.e. 0.93), which is in semi-quantitative agreement with the obtained parameters (1.19 and 1.09). The effect of oxygen inclusion: diradicals 1 and 2. The situation becomes somewhat more complicated from the quantitative point of view with the inclusion of oxygen atom into the position 3 of 1,4-diradicals. The main problem is the fact that there are now two orthogonal lone pairs, which can play the role of "relay-antennas". The case of 3,4-dioxabutane-1,4-diyl (2) described above, turned out to be simpler. The NBO analysis of the CASSCF wavefunction, shows that the odd-electron orbital at O4 is always overlapping with O3's 2p-orbital (not $\mathbf{s p}^{\mathbf{2}}$ ) which amounts to conformation-independent spin polarization. Thus the SOC two-dimensional dependence has only one maximum (see Figure 3) related to the conformation depicted in Figure 3 , and it is the O3's $2 \mathbf{p}$ orbital which acts as a "relay". This dependence, again, is reduced to the behavior of the parent trimethylene. For the Paternò-Büchi diradical 1, the 2p-orbital at $\mathrm{C} 4$ can be enforced to overlap either with the oxygen's $2 \mathbf{p}$ or $\mathbf{s p}^{2}$ hybrids via the terminal methylene rotation. One would then expect two areas of enhanced SOC values for the conformational dependence in diradical 1 (Figure 13). The first area (in the vicinity $110^{\circ}$ [ccoc] $-20^{\circ}$ [hcco]) is clearly related to the situation described above for the diradical $\mathbf{2}$. In this conformation the $2 \mathbf{p}$ orbital at $\mathrm{C} 4$ is overlapping with the $2 \mathbf{p}$ orbital of $\mathrm{O} 3$ and at the same time the mutual orientation of the $2 \mathbf{p}(\mathrm{C} 1)-2 \mathbf{p}(\mathrm{O} 3)$ pair of orbitals in the $\mathrm{C}-\mathrm{C}-\mathrm{O}$ fragment is similar to that in the maximum SOC conformation for the trimethylene itself, see Figure 10 (cf. Figure 3). 


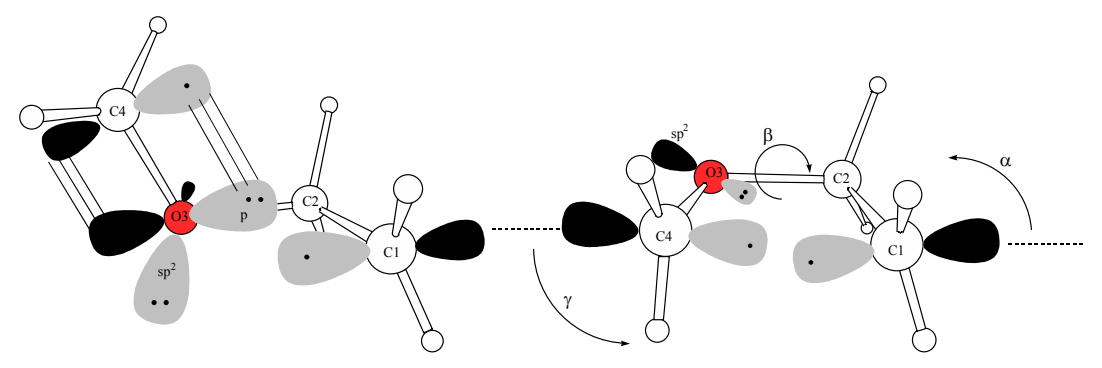

Figure 11. The $\{80 ; 110 ; 20\}$ conformation (left) and the s-cis conformation of the Paternò-Büchi intermediate.

The second area of elevated SOC values is associated with the s-cis conformation of the CCOC fragment (Figure 10). In s-cis conformation the SOC matrix element reaches its minimum at $\mathrm{d}(\mathrm{hcco})=0^{\circ}$ (notice the "mountain valley", Figure 11), and its maximum in the vicinity of $90^{\circ}$. A simple rationale for this is the controlling overlap between C4's $2 \mathbf{p}$ orbital and oxygen's $\mathbf{s p}^{2}$ (not $\mathbf{p}$ this time). The $\mathbf{p}(\mathrm{C} 4)-\mathbf{s p}^{2}(\mathrm{O} 3)-\mathbf{p}(\mathrm{C} 1)$ triad in the s-cis conformation is, again, reminiscent of the trimethylene situation. In this case it is the oxygen's $\mathbf{s p}^{2}$ orbital which plays the role of a "relay/antenna".

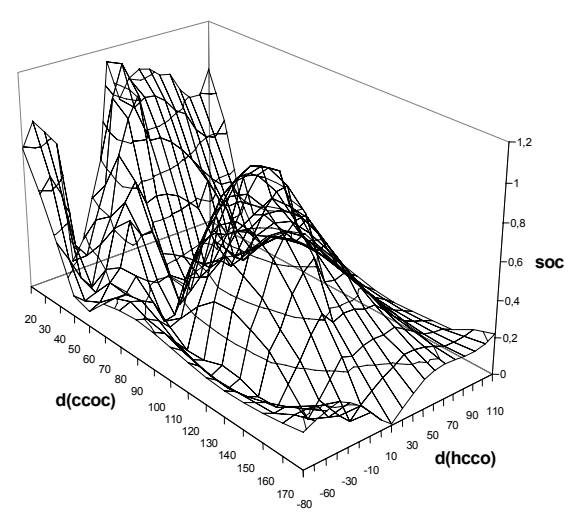

Figure 12. 2D dependence of Spin-Orbit Coupling in Paternò-Büchi intermediate 2.

We reported on the conformational behavior of SOC in the Paternò-Büchi parent system, $\mathrm{CH}_{2}-\mathrm{CH}_{2}-\mathrm{O}-\mathrm{CH}_{2}$, and refer the reader to this publication (ref. $4 \mathrm{k}$ ). In the present studies we extended the scope and computed the SOC matrix element values for a series of polycyclic compounds to demonstrate that the conceptually simple generalization for predicting SOCs described above is applicable to these more complex triplet diradicals (see Table 1). These systems, in which conformational freedom of the C-C-O-C fragment is restricted, clearly 
demonstrate the same general dependence of the magnitude of SOC on the three dihedral angles as the parent unsubstituted compounds.

Table 1. Ab initio SOC matrix elements for Paternò-Büchi diradicals with fixed molecular geometry

\begin{tabular}{|c|c|c|c|c|c|}
\hline Diradical $^{\mathrm{a}}$ & $\begin{array}{c}\text { Dihedral } \\
\mathrm{C}_{\alpha} \mathrm{O}_{\beta} \mathrm{C}_{\gamma} \mathrm{C}_{\delta}\end{array}$ & $\begin{array}{c}\text { Pyramidalization } \\
\text { and dihedrals } \\
\text { related to } \mathrm{C}_{\alpha}\end{array}$ & $\begin{array}{c}\text { Pyramidalization } \\
\text { and dihedrals } \\
\text { related to } \mathrm{C}_{\delta}\end{array}$ & $\begin{array}{c}\text { CASSCF }^{\mathrm{c}} \\
\Delta \mathrm{E}_{\mathrm{T}-\mathrm{S}} \\
(\mathrm{kcal} / \mathrm{mol})\end{array}$ & $\begin{array}{c}\operatorname{soc}^{d} \\
\left(\mathrm{~cm}^{-1}\right)\end{array}$ \\
\hline & 86.1 & $\begin{array}{c}164.2 \\
\mathrm{c}_{4} \mathrm{c}_{3} \mathrm{O}_{2} \mathrm{c}_{1}=20.0 \\
\mathrm{~h}_{3} \mathrm{c}_{3} \mathrm{O}_{2} \mathrm{c}_{1}=164.5\end{array}$ & $\begin{array}{c}143.2 \\
\mathrm{c}_{7} \mathrm{c}_{8} \mathrm{c}_{1} \mathrm{o}_{2}=-118.1 \\
\mathrm{~h}_{8} \mathrm{c}_{8} \mathrm{c}_{1} \mathrm{O}_{2}=46.4\end{array}$ & 0.73 & 0.361 \\
\hline & 91.1 & $\begin{array}{c}143.0 \\
\mathrm{c}_{1} \mathrm{c}_{2} \mathrm{O}_{3} \mathrm{c}_{4}=23.2 \\
\mathrm{~h}_{2} \mathrm{c}_{2} \mathrm{O}_{3} \mathrm{c}_{4}=167.5\end{array}$ & $\begin{array}{c}161.8 \\
\mathrm{c}_{6} \mathrm{c}_{5} \mathrm{c}_{4} \mathrm{O}_{3}=-107.8 \\
\mathrm{~h}_{5} \mathrm{c}_{5} \mathrm{c}_{4} \mathrm{O}_{3}=53.7\end{array}$ & 0.73 & 0.027 \\
\hline & 66.6 & $\begin{array}{c}139.6 \\
\mathrm{c}_{4} \mathrm{c}_{3} \mathrm{O}_{2} \mathrm{c}_{1}=5.0 \\
\mathrm{~h}_{3} \mathrm{c}_{3} \mathrm{O}_{2} \mathrm{c}_{1}=147.5\end{array}$ & $\begin{array}{c}151.1 \\
\mathrm{c}_{5} \mathrm{c}_{6} \mathrm{c}_{1} \mathrm{o}_{2}=-72.0 \\
\mathrm{~h}_{6} \mathrm{c}_{6} \mathrm{c}_{1} \mathrm{o}_{2}=79.6\end{array}$ & 0.68 & 0.065 \\
\hline & 61.0 & $\begin{array}{c}144.7 \\
\mathrm{c}_{4} \mathrm{c}_{3} \mathrm{O}_{2} \mathrm{c}_{1}=-6.7 \\
\mathrm{~h}_{3} \mathrm{c}_{3} \mathrm{O}_{2} \mathrm{c}_{1}=-151.2\end{array}$ & $\begin{array}{c}161.9 \\
\mathrm{c}_{5} \mathrm{c}_{6} \mathrm{c}_{1} \mathrm{O}_{2}=-52.7 \\
\mathrm{~h}_{6} \mathrm{c}_{6} \mathrm{c}_{1} \mathrm{o}_{2}=108.2\end{array}$ & 0.46 & 0.541 \\
\hline & 84.9 & $\begin{array}{c}141.7 \\
\mathrm{c}_{1} \mathrm{c}_{7} \mathrm{O}_{6} \mathrm{c}_{5}=3.2 \\
\mathrm{~h}_{7} \mathrm{c}_{7} \mathrm{O}_{6} \mathrm{c}_{5}=147.0\end{array}$ & $\begin{array}{c}157.1 \\
\mathrm{c}_{3} \mathrm{c}_{4} \mathrm{c}_{5} \mathrm{O}_{6}=-52.8 \\
\mathrm{~h}_{4} \mathrm{c}_{4} \mathrm{c}_{5} \mathrm{O}_{6}=101.4\end{array}$ & 0.06 & 0.286 \\
\hline & 0.0 & $\begin{array}{c}178.0 \\
\mathrm{c}_{3} \mathrm{c}_{2} \mathrm{O}_{1} \mathrm{c}_{5}=0.0 \\
\mathrm{~h}_{2} \mathrm{c}_{2} \mathrm{O}_{1} \mathrm{c}_{5}=180.0\end{array}$ & $\begin{array}{c}173.1 \\
\mathrm{c}_{3} \mathrm{c}_{4} \mathrm{c}_{5} \mathrm{O}_{1}=0.0 \\
\mathrm{~h}_{4} \mathrm{c}_{4} \mathrm{c}_{5} \mathrm{O}_{1}=180.0\end{array}$ & 0.81 & 0.012 \\
\hline & -28.2 & $\begin{array}{c}147.4 \\
\mathrm{c}_{1} \mathrm{c}_{2} \mathrm{O}_{3} \mathrm{c}_{4}=-22.3 \\
\mathrm{~h}_{2} \mathrm{c}_{2} \mathrm{O}_{3} \mathrm{c}_{4}=-167.9\end{array}$ & $\begin{array}{c}167.0 \\
\mathrm{c}_{6} \mathrm{c}_{5} \mathrm{c}_{4} \mathrm{O}_{3}=46.0 \\
\mathrm{~h}_{5} \mathrm{c}_{5} \mathrm{c}_{4} \mathrm{O}_{3}=-148.8\end{array}$ & 0.65 & 0.512 \\
\hline & -52.8 & $\begin{array}{c}115.2 \\
\mathrm{c}_{6} \mathrm{c}_{1} \mathrm{O}_{7} \mathrm{c}_{4}=-58.8 \\
\mathrm{c}_{2} \mathrm{c}_{1} \mathrm{O}_{7} \mathrm{c}_{4}=59.4\end{array}$ & $\begin{array}{c}151.0 \\
\mathrm{c}_{2} \mathrm{c}_{3} \mathrm{c}_{4} \mathrm{O}_{7}=28.5 \\
\mathrm{~h}_{3 \mathrm{x}} \mathrm{c}_{3} \mathrm{c}_{4} \mathrm{O}_{7}=-123.3\end{array}$ & 1.32 & 0.018 \\
\hline
\end{tabular}


Table 1. Continued

\begin{tabular}{|c|c|c|c|c|c|}
\hline Diradical $^{\mathrm{a}}$ & $\begin{array}{l}\text { Dihedral } \\
\mathrm{C}_{\alpha} \mathrm{O}_{\beta} \mathrm{C}_{\gamma} \mathrm{C}_{\delta}\end{array}$ & $\begin{array}{c}\text { Pyramidalization }^{b} \\
\text { and dihedrals } \\
\text { related to } \mathrm{C}_{\alpha} \\
\end{array}$ & $\begin{array}{c}\text { Pyramidalization }^{\mathrm{b}} \\
\text { and dihedrals } \\
\text { related to } \mathrm{C}_{\delta} \\
\end{array}$ & $\begin{array}{c}\mathrm{CASSCF}^{\mathrm{c}} \\
\Delta \mathrm{E}_{\mathrm{T}-\mathrm{S}} \\
(\mathrm{kcal} / \mathrm{mol}) \\
\end{array}$ & $\begin{array}{c}\operatorname{soc}^{d} \\
\left(\mathrm{~cm}^{-1}\right)\end{array}$ \\
\hline & 77.8 & $\begin{array}{c}143.0 \\
\mathrm{c}_{1} \mathrm{c}_{7} \mathrm{O}_{6} \mathrm{c}_{5}=8.0 \\
\mathrm{~h}_{7} \mathrm{c}_{7} \mathrm{O}_{6} \mathrm{c}_{5}=152.8\end{array}$ & $\begin{array}{c}150.4 \\
\mathrm{c}_{3} \mathrm{c}_{4} \mathrm{c}_{5} \mathrm{O}_{6}=-107.9 \\
\mathrm{~h}_{4} \mathrm{c}_{4} \mathrm{c}_{5} \mathrm{O}_{6}=43.2\end{array}$ & 0.50 & 0.338 \\
\hline & -42.0 & $\begin{array}{c}137.7 \\
\mathrm{c}_{4} \mathrm{c}_{3} \mathrm{O}_{2} \mathrm{c}_{1}=-31.5 \\
\mathrm{~h}_{3} \mathrm{c}_{3} \mathrm{O}_{2} \mathrm{c}_{1}=-170.1\end{array}$ & $\begin{array}{c}140.5 \\
\mathrm{c}_{5} \mathrm{c}_{6} \mathrm{c}_{1} \mathrm{o}_{2}=88.1 \\
\mathrm{~h}_{6} \mathrm{c}_{6} \mathrm{c}_{1} \mathrm{O}_{2}=-55.6\end{array}$ & 1.23 & 0.427 \\
\hline & 78.0 & $\begin{array}{c}142.1 \\
\mathrm{c}_{4} \mathrm{c}_{3} \mathrm{O}_{2} \mathrm{c}_{1}=9.9 \\
\mathrm{~h}_{3} \mathrm{c}_{3} \mathrm{O}_{2} \mathrm{c}_{1}=153.8\end{array}$ & $\begin{array}{c}158.4 \\
\mathrm{c}_{6} \mathrm{c}_{10} \mathrm{c}_{1} \mathrm{o}_{2}=-103.8 \\
\mathrm{~h}_{10} \mathrm{c}_{10} \mathrm{c}_{1} \mathrm{o}_{2}=53.4\end{array}$ & 0.68 & 0.278 \\
\hline & -0.3 & $\begin{array}{c}148.5 \\
\mathrm{c}_{1} \mathrm{c}_{2} \mathrm{O}_{3} \mathrm{c}_{4}=-64.9 \\
\mathrm{c}_{11} \mathrm{c}_{2} \mathrm{O}_{3} \mathrm{c}_{4}=65.6\end{array}$ & $\begin{array}{c}149.6 \\
\mathrm{c}_{6} \mathrm{c}_{5} \mathrm{c}_{4} \mathrm{O}_{3}=66.2 \\
\mathrm{c}_{9} \mathrm{c}_{5} \mathrm{c}_{4} \mathrm{O}_{3}=-65.7\end{array}$ & 0.056 & 0.033 \\
\hline & -56.5 & $\begin{array}{c}133.1 \\
\mathrm{c}_{9} \mathrm{c}_{1} \mathrm{O}_{2} \mathrm{c}_{3}=63.1 \\
\mathrm{c}_{8} \mathrm{c}_{1} \mathrm{O}_{2} \mathrm{c}_{3}=-66.1\end{array}$ & $\begin{array}{c}164.9 \\
\mathrm{c}_{5} \mathrm{c}_{4} \mathrm{c}_{3} \mathrm{O}_{2}=56.1 \\
\mathrm{~h}_{4} \mathrm{c}_{4} \mathrm{c}_{3} \mathrm{O}_{2}=-139.4\end{array}$ & -1.59 & 0.083 \\
\hline & 0.0 & $\begin{array}{c}148.9 \\
\mathrm{c}_{9} \mathrm{c}_{1} \mathrm{o}_{2} \mathrm{c}_{3}=-71.9 \\
\mathrm{c}_{10} \mathrm{c}_{1} \mathrm{o}_{2} \mathrm{c}_{3}=71.9\end{array}$ & $\begin{array}{c}150.7 \\
\mathrm{c}_{11} \mathrm{c}_{4} \mathrm{c}_{3} \mathrm{O}_{2}=72.5 \\
\mathrm{c}_{5} \mathrm{c}_{4} \mathrm{c}_{3} \mathrm{O}_{2}=-72.5\end{array}$ & 0.96 & 0.005 \\
\hline
\end{tabular}

${ }^{a} \mathrm{ROHF} / 3-21 \mathrm{G}$ geometries are presented. ${ }^{\mathrm{b}}$ pyramidalization for the radical center is defined as the angle between $\alpha-\beta$ (or $\gamma-\delta$ ) bond and a line dissecting two other bonds at given center, (180 degree is a planar geom.). ${ }^{\mathrm{c}} \mathrm{CASSCF}(4,4) / 6-31 \mathrm{G}(\mathrm{d}) / / \mathrm{ROHF} / 3-21 \mathrm{G}$. ${ }^{\mathrm{d}} \mathrm{M}$.A. Robb's state-averaged approach (as implemented in Gaussian98). 
One notices that the SOC values presented in Table 1 qualitatively follow the dependence shown in Figure 11. While we have not yet fully completed the numeric parameterization for the Paternò-Büchi diradicals, we hope that the findings presented in this paper are a clear demonstration that a simple generalized approach to such parameterization of spin-orbit coupling in the 1,3 and 1,4 organic triplet diradicals is feasible.

The importance of this task is most obvious for modeling photochemical behavior in biological systems. Computations of spin-orbit and other non-adiabatic coupling elements are extremely sensitive to the quality of the wavefunction. Even with all the spectacular progress in computational hardware development, it will take time before high level ab initio methods will be available for large molecules. The practical computational modeling for biological molecules is limited to various force field methods, which have been carefully fine-tuned over the years to accurately describe the ground states. Photochemistry adds another dimension of complexity to this task. Predicting the course of a photochemical reaction require not only accurate force fields but also non-adiabatic coupling elements to evaluate the probabilities of surface hopping. The latter is blissfully lacking. We hope that our efforts toward parameterization of conformational behavior of SOC will help to fill this void.

\section{Computational Details}

$\mathrm{Ab}$ initio computations were carried out with Gaussian 98 package 9 on a dual R10000 mips processor SGI Octane workstation equipped with 1GB memory. The initial geometries were optimized at ROHF/3-21G(d) or ROHF/6-31G(d) methods and the spin-orbit coupling elements were computed with one-electron spin-orbit Hamiltonian with parameterized (effective) nuclear charges in conjunction with a state-averaged MCSCF wave function as implemented by Robb. The link L319 (a G98 module for computing atomic spin-orbit integrals) was modified and recompiled to include effective charges optimized by Koseki et al. ${ }^{12}$ Singlet-triplet energy separations presented in Table 1 for large polycyclic structures are computed at CASSCF/6$31 \mathrm{G}(\mathrm{d})$ level. In the parent $\mathrm{CH}_{2}-\mathrm{CH}_{2}-\mathrm{O}-\mathrm{CH}_{2}$ diradical the $\mathrm{S}-\mathrm{T}$ gaps were computed utilizing a multireference CASSCF(6,6)-MP2/6-311+G(d) level of theory to account for dynamic correlation.

\section{Acknowledgements}

Support of this research by the National Science Foundation is gratefully acknowledged. 


\section{References and Notes}

1. Salem, L.; Rowland, C. Angew. Chem., Int. Ed. 1972, 11, 92. The Electronic Properties of Diradicals.

2. For reviews see (a) Borden, W. T. Diradicals; John Wiley \& Sons: New York, 1982. (b) Michl, J.; Bonacic-Koutecký, V. Electronic Aspects of Organic Photochemistry; John Wiley \& Sons: New York, 1990. (c) Platz, M. S.; Ed. Kinetics and Spectroscopy of Carbenes and Diradicals; Plenum: NY, 1990. (d) Klessinger, M.; Michl, J. Excited States and Photochemistry of Organic Molecules; VCH Publishers: NY, 1995. (e) Kutateladze, A. G.; Ed. Computational Methods in Photochemistry; Dekker/CRC Press: Boca Raton, FL, 2004.

3. (a) Zimmt, M. B.; Doubleday, C.; Gould, I. R.; Turro, N. J. J. Am.Chem. Soc. 1985, 107, 6724. (b) Zimmt, M. B.; Doubleday, C.; Turro, N. J. J. Am. Chem. Soc. 1985, 107, 6726.

4. Michl, J. J. Am. Chem. Soc. 1996, 118, 3568. (b) Substitutent effects in 1,3cyclopentanediyls: Kita, F.; Adam, W.; Jordan, P.; Nau, W. M.; Wirz, J. J. Am. Chem. Soc. 1999, 121, 9265. (c) Kita, F.; Nau, W. M.; Adam, W.; Wirtz, J. J. Am. Chem. Soc. 1995, 117, 8670. NBO dissection of SOC: (d) Zimmerman, H. E.; Kutateladze, A. G. J. Am. Chem. Soc. 1996, 118, 249. (e) Zimmerman, H. E.; Kutateladze, A. G. J. Org. Chem. 1995, 60 (19), 6008. (f) Zimmerman, H. E.; Kutateladze, A. G.; Maekawa, Y.; Mangette, J. E. J. Am. Chem. Soc. 1994, 116, 9795; (g) Michl, J.; Havlas, Z. Pure Appl.Chem. 1997, 69, 785. (h) Havlas, Z.; Downing, J. W.; Michl, J. J. Phys.Chem. A 1998, 102, 5681. (i) Bockmann, M.; Klessinger, M.; Zerner, M. J. Phys. Chem. 1996, 100, 10570. SOC in tetramethylene. (j) Klessinger, M. Pure Appl. Chem. 1997, 69, 773. (k) Kutateladze, A. G. J. Am. Chem. Soc. 2001, 123, 9279.

5. Doubleday, D.; McIver, J.W.; Page, M.J. J. Am. Chem. Soc. 1982, 104, 6533. (b) Carlacci, L.; Doubleday, D.; Furlani, T.; King, H.; McIver, J. W., Jr. J. Am. Chem. Soc. 1987, 109, 5323.

6. Caldwell, R. A.; Majima, T.; Pac, C. J. Am. Chem. Soc. 1982, 104, 629.

7. Caldwell, R. A. In Kinetics and Spectroscopy of Carbenes and Biradicals, Platz, M. S., Ed.; Plenum: New York, 1990; p 102.

8. We define a partially conjugated spacer as a tether, which has (i) at least one $\mathrm{sp}^{3}$ carbon, interrupting the $\pi$-conjugation and (ii) at least one moiety capable of $\pi-\pi$ or $n-\pi$ conjugation with either radical center. In this paper the $\mathrm{C}$-centered radical that is not conjugated (i.e. adjacent to the $\mathrm{sp}^{3}$ carbon) is numbered " 1 " for uniformity sake.

9. Frisch, M. J.; Trucks, G. W.; Schlegel, H. B.; Scuseria, G. E.; Robb, M. A.; Cheeseman, J. R.; Zakrzewski, V. G.; Montgomery, J. A., Jr.; Stratmann, R. E.; Burant, J. C.; Dapprich, S.; Millam, J. M.; Daniels, A. D.; Kudin, K. N.; Strain, M. C.; Farkas, O.; Tomasi, J.; Barone, V.; Cossi, M.; Cammi, R.; Mennucci, B.; Pomelli, C.; Adamo, C.; Clifford, S.; Ochterski, J.; Petersson, G. A.; Ayala, P. Y.; Cui, Q.; Morokuma, K.; Malick, D. K.; Rabuck, A. D.; Raghavachari, K.; Foresman, J. B.; Cioslowski, J.; Ortiz, J. V.; Stefanov, B. B.; Liu, G.; Liashenko, A.; Piskorz, P.; Komaromi, I.; Gomperts, R.; Martin, R. L.; Fox, D. J.; Keith, T.; 
Al-Laham, M. A.; Peng, C. Y.; Nanayakkara, A.; Gonzalez, C.; Challacombe, M.; Gill, P. M. W.; Johnson, B.; Chen, W.; Wong, M. W.; Andres, J. L.; Gonzalez, C.; Head-Gordon, M.; Replogle, E. S.; Pople, J. A. Gaussian 98, Revision A.6; Gaussian, Inc.: Pittsburgh, PA, 1998.

10. for review see Reed, A. E.; Curtiss, L. A.; Weinhold, F. Chem. Rev. 1988, 88, 899.

11. We also utilized a more conventional active space 2,2 with very similar results

12. Koseki, S.; Gordon, M. S.; Schmidt, M. W.; Matsunaga, N. J. Phys.Chem. 1995, 99, 12764. 